\title{
O talk show na escola
}

Myrian Clark Giannini

Jornalista, especialista em Educomunicação e mestranda em Ciências da Comunicação na Escola de Comunicação e Artes (ECA) da Universidade de São Paulo (USP).

E-mail: myrianclark@gmail.com

Maria Cristina Castilho Costa

Doutora em Ciências Sociais pela Faculdade de Filosofia, Letras e Ciências Humanas

(FFLCH) da Universidade de São Paulo (USP), professora titular de Comunicação e Cultura da Escola de Comunicação e Artes (ECA) da USP, docente do curso de licenciatura em Educomunicação e coordenadora do Observatório de Comunicação, Liberdade de Expressão e Censura da USP.

E-mail: criscast@usp.br

Resumo: A passagem pelo ensino médio impõe aos jovens decisões, desafios e mudanças. No entanto, há um esvaziamento dos espaços de diálogo nas escolas. Nesta experiência - executada como monografia apresentada para obtenção do título de especialista em Educomunicação em 2015 -, alunos atuaram em grupo e desempenharam diferentes papéis na produção de um talk show, desfrutando de diálogos enriquecedores e de uma vivência do universo do trabalho e da pesquisa. Esse processo permitiu avaliar relacionamentos interpessoais, práticas educomunicativas, além de possibilitar a leitura crítica dos meios de comunicação e a ressignificação das informações do mundo complexo em que vivemos. As práticas educomunicativas da pesquisa foram registradas num diário de campo e somam forças para que outros educadores reflitam, renovem e ampliem a comunicação no ambiente escolar.

Palavras-chave: educomunicação; adolescentes; talk show; etnografia; ensino médio.
Abstract: The passage through high school imposes decisions, challenges and changes upon teenagers. However, there is a lack of areas for dialogues at schools. In this experience - conducted as a monograph defended to obtain the title of specialist in Educommunication in 2015 -, students worked in groups and played different roles in the production of a talk show, experiencing enriching dialogues, as well as the universe of work and research. This process allowed us to evaluate interpersonal relationships, educommunicative practices, and also enabled the critical reading of means of communication and the resignification of the information of the complex world we live in. The educommunicative practices of the research were recorded in a field diary and join forces so that educators can reflect on, renew, and expand communication at schools.

Keywords: educommunication; teenagers; talk show; ethnography; high school.

\section{INTRODUÇÃO}

Uma parcela significativa dos adolescentes, e também da sociedade atual, tem sua formação e visão de mundo baseadas nos meios de comunicação. Mas as escolas - tanto públicas quanto privadas - ainda carecem de ações que propiciem um contato maior com os veículos de comunicação de massa e desenvolvam, a 
partir dessa ligação, um terreno favorável ao diálogo. O descompasso entre os conteúdos do dia a dia escolar e o mundo permeado pelos meios de comunicação de massa (MCM) nos levou à educomunicação. Nesse novo campo da ciência, procura-se introduzir os meios de comunicação na sala de aula e aproximá-los dos conteúdos escolares. O objetivo da educomunicação é também promover discussões e ressignificações daquilo que é veiculado nos próprios MCM. Nessa perspectiva surgiu a ideia do projeto "O talk show na escola", uma experiência executada como monografia do curso de pós-graduação lato sensu em Educomunicação na Escola de Comunicações e Artes da Universidade de São Paulo (ECA-USP) em 2015, sob orientação da Prof. Dra. Maria Cristina Castilho Costa.

A proposta foi desenvolvida com alunos do segundo ano do ensino médio no Colégio Marista Arquidiocesano, uma instituição particular do bairro Vila Mariana, na cidade de São Paulo. Os alunos foram convidados a montar um programa de entrevistas no colégio, passando por todas as etapas: da pauta inicial à produção de roteiro até a gravação da entrevista. Nesse processo procuramos desenvolver um conjunto de ações educomunicativas para a produção coletiva do talk show. Para além da realização de um programa, buscamos o diálogo, a reflexão e a leitura crítica dos meios. Ao lado dessas constatações estava nossa experiência no Programa do Jô, veiculado de 2000 a 2016 na TV Globo. Por quinze anos trabalhamos como redatora, editora, repórter e produtora neste veículo.

\section{O DIÁLOGO E O TALK SHOW}

Segundo Gadotti, para Paulo Freire ${ }^{1}$ o diálogo não é apenas um método, mas uma estratégia para respeitar o saber do aluno que chega à escola. "Para pôr o diálogo em prática, o educador não pode colocar-se na posição ingênua de quem se pretende detentor de todo o saber; deve, antes, colocar-se na posição humilde de quem sabe que não sabe tudo." Segundo Cristina Costa ${ }^{2}$,

[...] sabe-se que da escola se espera muito mais do que a alfabetização e o desenvolvimento da cidadania e do nacionalismo, que se cobra da escola uma participação maior na formação dos indivíduos e no apoio às difíceis condições de vida que eles enfrentam no mundo contemporâneo. Pois bem, esses são argumentos para que deixemos para trás uma metodologia educacional aristocrática, seletiva, ilustrada e erudita para adotarmos uma postura mais realista de valorização do educando, de sua bagagem cultural e das necessidades que ele manifesta como cidadão.

Além do respeito ao universo dos alunos, procuramos jogar alguma luz sobre a falta de engajamento dos adolescentes com o universo escolar. Salvo raras exceções, é comum ouvir pais, alunos e professores - tanto de escolas públicas quanto privadas - lamentarem a desmotivação dos educandos com a escola, especialmente com os conteúdos curriculares. Dados alarmantes de evasão escolar e fraco desempenho dos alunos brasileiros nas avaliações internacionais como o Programa Internacional de Avaliação de Alunos (Pisa) levaram nossa 
sociedade a refletir mais detidamente sobre o tema. A busca do diálogo entre comunicação e educação se faz necessária, e esta pesquisa é mais um passo nesse sentido. Os adolescentes têm uma cultura centrada nas tecnologias da informação, que também reconfiguram as práticas sociais da geração. Nesse sentido, é colocado aos educadores o desafio de recuperar a relevância da escola e a motivação dos alunos em relação a ela. O desenvolvimento de projetos educomunicativos nas escolas encontra eco no pensamento de Citelli ${ }^{3}$.

Ignorar essa discussão revela-se, em última instância, uma forma pouco educativa, pois abandona à lógica dos próprios veículos os sentidos das mensagens nele gerados e isso pode servir a tudo, menos à proclamada vontade social de construção da cidadania.

Neste experimento os alunos lidaram com a produção áudio visual e o desenvolvimento de um letramento voltado à leitura crítica da mídia. Não podemos afirmar que a câmera será a caneta das futuras gerações. Mas formar bons "escritores" nesse novo mundo digital é um dos objetivos educacionais que consideramos fundamentais. O talk show mostrou-se um bom gênero para cultivar o diálogo no ambiente escolar e também para ajudar na formação de um público menos ingênuo e, portanto, mais exigente. Em dezembro de 2016 se encerrou a última temporada do Programa do Jô, fazendo dele o mais longevo do gênero até hoje. A longevidade do programa se somou aos fatos anteriormente descritos para a escolha dele como ponto de partida com os alunos.

\section{METODOLOGIA}

A metodologia desenvolvida nos encontros do grupo Talk Show na Escola teve como base o pensamento do professor e doutor em sociologia Michel Thiollent ${ }^{4}$, um dos principais proponentes da pesquisa-ação.

A pesquisa-ação é um tipo de pesquisa social com base empírica que é concebida e realizada em estreita associação com uma ação ou com uma resolução de um problema coletivo e no qual os pesquisadores e os participantes representativos da situação ou do problema estão envolvidos de modo cooperativo ou participativo.

A pesquisa-ação se baseia teoricamente no conceito de educação libertadora e cria espaços onde as pessoas participam do projeto de atuação. Na pesquisa-ação o "conhecer" e o "agir" acontecem ao mesmo tempo, mas uma pesquisa só pode ser assim qualificada "quando houver realmente uma ação por parte das pessoas ou grupos implicados no problema sob observação". Durante a maior parte dos encontros os alunos trabalharam em grupos. Segundo Cristina $\operatorname{Costa}^{5}$, "quando se trabalha com meios de comunicação é imprescindível a formação de equipes, pois não há trabalho individual em rádio, TV ou vídeo". O grupo de alunos exerceu a experiência da tomada de decisões em conjunto. A base de nossa postura e mediação dos diálogos foi a escuta, elucidando
3. CITELLI, Adilson. Educação e mudanças: novos modos de conhecer. In: _____ (Org.). Outras linguagens na escola: publicidade, cinema e TV, jogos, informática. São Paulo: Cortez, 2000, p. 28.

4. THIOLLENT, Michel. Metodologia da pesquisa-ação. São Paulo: Cortez, 2011, p. 21.

5. COSTA, Cristina. Educação, imagem e mídias. São Paulo: Cortez, 2013, p. 153. 
aspectos das situações colocadas sem imposição unilateral de nossas próprias convicções. Diz Thiollant:

Na pesquisa-ação os pesquisadores desempenham um papel ativo no equacionamento dos problemas encontrados, no acompanhamento e na avaliação das ações desencadeadas em função dos problemas. Sem dúvida, a pesquisa-ação exige uma estrutura de relação entre pesquisadores e pessoas da situação investigada que seja de tipo participativo ${ }^{6}$.

Procuramos ter em mente algumas questões: como os professores propiciam situações de diálogo enriquecedoras? Em qual momento acontece esse diálogo? Esse conteúdo pode ser propositalmente relacionado com o aprendizado em sala de aula? É possível fazer uma análise estética das mensagens audiovisuais e digitais? Como avaliar os resultados desses encontros? Que tipo de contribuição poderíamos legar aos educadores? Seria possível reunir essas estratégias e passá-las aos professores?

Também guiamos nossas ações pela etnografia, ou observação participante. A etnografia parte de uma visão que engloba, para além do objeto de estudo, questões informadas pela sociedade como um todo. Para Yves Winkin ${ }^{7}$,

a etnografia hoje é ao mesmo tempo uma arte e uma disciplina científica, que consiste em primeiro lugar em saber ver. É em seguida uma disciplina que exige saber estar com, com outros e consigo mesmo, quando você se encontra perante outras pessoas. Enfim, é uma arte que exige que se saiba retraduzir para um público terceiro (terceiro em relação àquele que você estudou) e portanto que se saiba escrever. Arte de ver, arte de ser, arte de escrever.

Mas o que difere a experiência obtida num trabalho como este dos longos textos de jornalistas literários, por exemplo, é nossa relação constante com a teoria. Para Winkin ${ }^{8}$,

Não é simplesmente para encaixar os dados numa reflexão mais conceitualizante ou, mais ambiciosamente, para tentar romper com o senso comum, como prescrevem Bourdieu, Chamboredon e Passeron, em Le métier de sociologue [...]. Não, é antes de tudo porque a teoria vai levar a ver mais e mais longe.

Portanto, o uso do trabalho etnográfico, a minúcia para o estudo do grupo

6. THIOLLENT, Michel. Metodologia da pesquisa-ação, op. cit., p. 22.

7. WINKIN, Yves. A nova comunicação: da teoria ao trabalho de campo. Campinas: Papirus, 1998, p. 130 .

8. Idem, p. 135

9. COELHO, Ruy. Dias em Trujillo: um antropólogo brasileiro em Honduras. São Paulo: Perspectiva, 2000. ou da situação podem levar a extrair muitas regularidades que nos permitem fundar um conjunto particular e aferir, do coração desse conjunto, questões universais. Com base na combinação dessas duas metodologias, construímos um diário de campo. Ali estão registros minuciosos dos encontros do grupo Talk Show na Escola, além de nossas considerações às práticas educomunicativas e dificuldades para implementá-las em sala de aula. Também assinalamos no diário reflexões sobre a atitude dos alunos no âmbito do grupo, nossas reações e impressões, os acontecimentos inesperados dos encontros, bem como fatores externos que os influenciaram. O livro Dias em Trujillo: um antropólogo brasileiro em Honduras, de Ruy Coelho, ${ }^{9}$ foi referência fundamental para a construção do diário de campo. 


\section{ORGANIZAÇÃO, PLANEJAMENTO E DINÂMICA DOS ENCONTROS}

As atividades na escola constaram de oito encontros de uma hora e meia de duração durante os meses de fevereiro e março, numa sala cedida pelo colégio. Os alunos foram avisados de que a atividade era gratuita, aconteceria no contraturno escolar e que manteríamos uma câmera no canto do ambiente apenas para registrar os encontros e facilitar as anotações no diário de campo. A presença dos alunos foi voluntária e o resultado do processo não alterou suas notas de avaliação. À direção da escola apresentamos o projeto, com a divisão das atividades e a cronometragem de cada etapa a ser realizada nos encontros. Nosso planejamento de aula determinava os minutos previstos para cada atividade e os materiais necessários - textos, vídeos, jornais impressos etc. Reunimos um grupo de vinte estudantes. Dentre eles estavam também quatro alunos oriundos de escolas públicas e patrocinados pela organização não governamental Instituto Social para Motivar, Apoiar e Reconhecer Talentos (ong Ismart). Trata-se de uma entidade privada, sem fins lucrativos, que identifica jovens talentos de baixa renda e lhes concede bolsas em escolas particulares de excelência. Os alunos da ong trouxeram um olhar diferenciado a respeito das questões debatidas entre o grupo, o que enriqueceu significativamente o diálogo. Para facilitar a comunicação com os alunos, criamos um grupo no aplicativo Whatsapp, que, ao longo da pesquisa, se tornou um fórum de comunicação. Ao todo, foram trocadas seiscentas mensagens.

No primeiro encontro começamos a ouvir dos alunos as preferências televisivas e os conhecimentos a respeito de talk shows brasileiros. Falamos sobre educomunicação, diálogo, aprender fazendo e media literacy. Explicitamos que o formato do Programa do Jô segue um modelo já testado em outros países: convidado, apresentador ilustre, plateia, banda e gravação da entrevista como se fosse ao vivo. A entrevista corre dando o sentido de espontaneidade e casualidade. A partir de alguns vídeos, os alunos tiveram oportunidade de discutir temas do monólogo de abertura e refletir sobre o texto a ser feito para o Talk Show da Escola. Nos encontros seguintes, partindo de uma premissa educomunicativa de diálogo e trabalho em grupo, os alunos dividiram tarefas e escreveram sugestões de pauta. Levamos a eles exemplos de pautas escritas pela produção do Programa do Jô. Discutimos a importância e as dificuldades do trabalho em equipe. Conversamos a respeito da melhor maneira para abordar alguém a ser entrevistado pelo programa. Para treinar a execução da pré-entrevista, que daria origem ao roteiro final do talk show, os alunos entrevistaram profissionais da escola. O diretor, Ascânio João Sedrez, foi entrevistado pelo grupo coletivamente. Os alunos o questionaram para além da pauta prevista e trouxeram temas pertinentes ao dia a dia escolar.

Para preparação dos roteiros também discutimos as fontes de pesquisa como forma de aprofundar e triar pautas. Os alunos vivenciaram a posição de entrevistador e entrevistado, escreveram roteiros e tiraram dúvidas em relação 
ao papel do ponto eletrônico e às incumbências de cada membro da equipe. Convidaram o público da escola para participar da plateia na gravação do talk show final, produziram cenário, figurino, escolheram os membros da banda e as músicas a serem executadas durante o programa final. Também definiram, por meio de votação, que o nome do programa seria Talk Show do Arqui.

O grupo escolheu como assunto do monólogo de abertura as pressões sobre os jovens para a escolha de uma carreira e definição de metas de vida. Em diversos momentos, ao executarem suas respectivas tarefas, os estudantes expuseram as próprias experiências, dilemas, dificuldades e angústias. Como forma de agradecimento à participação deles na pesquisa, levamos bolinhos caseiros feitos por nós para oferecer aos participantes ao final dos encontros. Tal ação se mostrou muito oportuna para o engajamento dos alunos, que reconheceram nessa atitude nosso empenho, seriedade e desejo de desenvolver a pesquisa.

No penúltimo encontro os alunos foram à TV Globo para assistir à gravação do Programa do Jô. Com apoio do Globo Universidade, área de relacionamento da empresa com o meio acadêmico e o público jovem, os estudantes também fizeram uma visita guiada pela empresa. No último encontro gravamos, no teatro da escola, um talk show totalmente produzido e conduzido pelos alunos. Por meio de votação, escolheram como entrevistado um professor estimado e famoso por ser um homem corpulento e alto, Silvio Bedani, o Silvão, professor de literatura. Também escolheram e conseguiram contatar a atriz e youtuber Bruna Louise, que se autointitula "A desbocada" e tem 1 milhão de inscritos em seu canal. A terceira entrevistada foi Maria Ivonete Gomes da Silveira, uma mulher que estava superando um tratamento de câncer com a prática de corridas e caminhadas.

\section{DESAFIOS}

As escolas, geralmente, estão ligadas a uma rotina, a programas e a atividades extremamente ordenadas, repetitivas e organizadas. Um universo assim não comporta facilmente um projeto de intervenção extracurricular, e qualquer iniciativa que fuja dessa programação previamente agendada implica o enfrentamento de diversos obstáculos. A agenda repleta de atividades e o excesso de compromissos dos jovens foi talvez um de nossos maiores desafios. A falta de familiaridade entre os meios de comunicação e o universo escolar exige do educomunicador um planejamento minucioso. Discutimos questões de poder, mídia, audiência, lógica de mercado e sociedade com os alunos. O educomunicador precisa estar suficientemente seguro e tranquilo também para escutar a respeito do universo dos alunos, saber estar com eles e poder, assim, refletir com eles. Não basta simplesmente disposição para fazer. É preciso inserir o novo, o inusitado, encontrar recursos, cativar as pessoas, conseguir adesão. Em nosso experimento, os bolinhos oferecidos no final dos encontros desempenharam 
um papel importante na construção dessa relação com os alunos. As aulas educomunicativas também demandam mais do ambiente escolar, do professor e dos alunos. Desenvolver uma produção de mídia com turmas numerosas de adolescentes também requer uma disposição do educomunicador para turmas "motivadas" e alunos "questionadores" e, nesse sentido, o Talk Show na Escola também pode contribuir para uma revisão dos papéis entre os sujeitos da escola. Um dos desafios da educomunicação, segundo Baccega ${ }^{10}$, "é levar o sujeito a ter consciência da construção da cultura na qual vivemos, da importância da comunicação na trama da cultura e, sobretudo, levá-lo ao conhecimento e à reflexão sobre as mediações que conformam nossas ações [...]”. Para obter êxito nesse desafio, é fundamental levar o sujeito a ter consciência de como se processam, em vários âmbitos, as práticas midiáticas que nos envolvem e que colaboram tão fortemente para a configuração de nossa identidade.

\section{MOTIVAÇÃO E PERTINÊNCIA}

Durante a pesquisa pudemos observar o quanto as práticas educomunicativas desenvolvem e disseminam o olhar crítico e a capacidade de questionamento do estudante a respeito do mundo que o cerca. Os alunos conheceram truques de bastidores, como a edição de áudio e a condução de ensaios. Com os vídeos e textos previamente selecionados para os encontros, debatemos questões éticas, trabalhamos a transdisciplinaridade e exercitamos uma série de saberes. Em nossa tradição escolar há prioridade de transferir grandes volumes de conteúdo aos alunos em detrimento do diálogo. Ismar de Oliveira Soares ${ }^{11}$, um dos mais conhecidos defensores da educomunicação e coordenador do Núcleo de Comunicação e Educação da Universidade de São Paulo (NCE-USP), diz que uma educação eficiente precisa se inserir no cotidiano dos estudantes, e não ser um simulacro de suas vidas. "Fazer sentido para eles significa partir de um projeto de educação que caminhe no mesmo ritmo que o mundo que os cerca e que acompanhe essas transformações. Que entenda o jovem. E não dá para entendê-lo sem sequer escutá-lo.” A educomunicação mostra que a escola pode ser um espaço transdisciplinar de cidadania, criatividade e expressão. Ao desenvolver o talk show, os alunos também organizaram informações, ressignificando-as e sistematizando-as. O grupo exercitou a responsabilidade, o senso crítico e o diálogo. Também apoiados em Freinet ${ }^{12}$, podemos dizer que o aprender deve passar pela experiência de vida. E isso só é possível pela ação, através do trabalho, que desenvolve o pensamento lógico e inteligente a partir de preocupações materiais, sendo que estas são um degrau para a abstração.

\section{CONCLUSÃO}

Por meio da interação e do diálogo pudemos atestar que muitos jovens mudaram de opinião, transformaram as relações pessoais com os demais
10. BACCEGA, Maria Aparecida. Comunicação/educação e a construção de nova variável histórica. In: CITELLI, Adilson Odair; COSTA, Maria Cristina Castilho (Org.). Educomunicação: construindo uma nova área de conhecimento. São Paulo: Paulinas, 2011, p. 4.

11. SOARES, Ismar de Oliveira. Educomunicação: 0 conceito, o profissional, a aplicação - contribuições para a reforma do ensino médio. São Paulo: Paulinas, 2011, p. 8.

12. SAMPAIO, Rosa Maria Whitaker. Freinet: evolução histórica e atualidades. São Paulo: Scipione, 2007, p. 10. 
membros do grupo e saíram transformados dos encontros. Ao revelar outras habilidades, a intervenção educomunicativa modificou o consagrado, alterou expectativas, criou o inusitado e abriu a possibilidade de ser diferente, fazer algo distinto do que todos fazem. Jenkins ${ }^{13}$ nos fala no mesmo sentido: um projeto educomunicativo pode fazer que "os jovens tenham uma atuação crítica e transformadora de sua própria realidade, e a de seus pares, o que envolve muitas outras competências que não são as restritas à habilidade no manejo técnico". A heterogeneidade e a diversidade, especialmente com a presença dos alunos da ong Ismart, trouxeram riqueza às discussões. Diante da perspectiva de "falar" para os colegas ou para a comunidade, o compromisso em relação à produção de texto ou imagem se tornou maior, uma vez que a produção também impactaria a identidade daqueles alunos perante a comunidade escolar, e não apenas serviria de parâmetro para a nota dada por um professor.

O Talk Show na Escola tinha como proposta inicial servir de estímulo para levar os meios de comunicação de massa para dentro da escola e, a partir deles, estabelecer canais dialógicos envolvendo alunos, professores e instituição. Transformou-se em uma das inúmeras ferramentas para fazer dos alunos protagonistas de seu conhecimento, engajá-los num trabalho cooperativo, defrontá-los com as próprias questões. Em nossa experiência, pudemos constatar que a utilização da cultura comunicacional em sala de aula, quando mediada por um educador, é extremamente enriquecedora para aprendizagem e construção da cidadania. Os dados colhidos e as conclusões alcançadas nos permitem afirmar que o experimento pode ser replicado também por outros educomunicadores e professores. Nesse sentido, não é preciso dominar as etapas de produção de um talk show. Quaisquer saberes servem de justificativa para construir uma ponte de diálogo na escola. Mesmo que esses saberes não sejam atividades profissionais, todo conhecimento, quando bem planejado e sistematizado, pode ser usado a favor da aprendizagem. A tecnologia se transforma, mas não substitui o homem. Ela será sempre um instrumento do qual ele se utiliza para se relacionar com o mundo. Daí a necessidade de a educomunicação estar sempre presente, renovando suas ações de acordo com as interfaces que se apresentem. Também podemos concluir que as práticas educomunicativas demandam tempo: para preparar aulas, para estar com os alunos, para escutá-los, para sistematizar os encontros e refletir sobre eles. Tal reflexão, muitas vezes relegada ou desprezada na vida cotidiana, embaça nossa visão de mundo. O moto-contínuo de vivência, especialmente nas grandes cidades, é o mesmo vivido pelos adolescentes. Viver sem tempo para a reflexão acaba por dificultar as tomadas de decisão e a construção de sentidos. A educomunicação pode ser um espaço para ajudar a transformar esse cenário.

Finalmente, com os dados obtidos na pesquisa podemos chegar a duas conclusões: a educomunicação é uma prática para o professor que queria renovar seu espaço de ensino e tenha uma visão abrangente da sociedade, enxergando a escola e seus alunos como partes integrantes desse contexto social mais amplo. Já para nós, educomunicadores, cuja missão é transformar a escola e 
promover a leitura crítica dos meios, buscando formar cidadãos conscientes de sua participação no mundo e das contribuições que podem dar à sociedade, a educomunicação é uma obrigação.

\section{REFERÊNCIAS BIBLIOGRÁFICAS}

BACCEGA, Maria Aparecida. Comunicação/educação e a construção de nova variável histórica. In: CITELLI, Adilson Odair; COSTA, Maria Cristina Castilho (Org.). Educomunicação: construindo uma nova área de conhecimento. São Paulo: Paulinas, 2011. p. 4-12.

BARBERO, Jesús Martin. Desafios culturais: da comunicação à educomunicação. In: CITELLI, Adilson Odair; COSTA, Maria Cristina Castilho (Org.). Educomunicação: construindo uma nova área de conhecimento. São Paulo: Paulinas, 2011. p. 122-134.

CITELLI, Adilson. Educação e mudanças: novos modos de conhecer. In: (Org.). Outras linguagens na escola: publicidade, cinema e TV, jogos, informática. São Paulo: Cortez, 2000.

COELHO, Ruy. Dias em Trujillo: um antropólogo brasileiro em Honduras. São Paulo: Perspectiva, 2000.

COSTA, Cristina. Educação, imagem e mídias. São Paulo: Cortez, 2013.

GADOTTI, Moacir (Org.). Paulo Freire: uma bibliografia. São Paulo: Cortez, 1996. Disponível em: <http:/ /seminario-paulofreire.pbworks.com/f/unid2_ ativ4paulofreire_umabiobibliografia.pdf >. Acesso em: 17 set. 2017.

JENKINS, Henry. Confronting the challenges of participatory culture: media education for the 21st century. Disponível em: <http:/ / www.curriculum.org/ secretariat/files/Sept30TLConfronting.pdf>. Acesso em: 17 set. 2017.

MALINOVSKI, Bronislaw. Os argonautas do Pacífico Ocidental. São Paulo: Victor Civita: 1984. (Coleção Pensadores)

SAMPAIO, Rosa Maria Whitaker Ferreira. Freinet: evolução histórica e atualidades. São Paulo: Scipione, 2007.

SOARES, Ismar de Oliveira. Educomunicação: o conceito, o profissional, a aplicação - contribuições para a reforma do ensino médio. São Paulo: Paulinas, 2011.

THIOLLENT, Michel. Metodologia da pesquisa-ação. São Paulo: Cortez, 2011.

WINKIN, Yves. A nova comunicação: da teoria ao trabalho de campo. Campinas: Papirus, 1998. 